\title{
Lake Tourism: An Integrated Approach to Lacustrine Tourism Systems
}

Edited by C. Michael Hall and Tuija Härkönen. Channel View Publications http://www.channelviewpublications.com 2006, xiii + 235 pp (maps, figures, tables, references) €64.95 Pbk. ISBN 1-84541-040-8 / EAN 978-1-84541-040-7

Wade L. Hadwen

Griffith University, Australia

Wade L. Hadwen Australian Rivers Institute

Griffith University Nathan Campus Brisbane, Queensland, Australia 4111

Tel: +61 737353987

Fax: +61 737357615

Email:w.hadwen@griffith.edu.au 
There is no doubt that being near, on or in water is an appealing component of many tourism and recreational pursuits (Tuohino and Pitkanen 2004). Nevertheless, the importance of freshwater ecosystems to the tourism industry has received surprisingly little attention in the literature. The $32^{\text {nd }}$ release from Channel View Publications Aspects of Tourism series, Lake Tourism: An Integrated Approach to Lacustrine Tourism Systems edited by C. Michael Hall and Tuija Härkönen aims to address the limited scholarly recognition of the role of aquatic environments in supporting tourism and recreation opportunities.

In Lake Tourism, Hall and Härkönen collate and integrate 10 interesting and extremely diverse case studies that relate to various aspects of water-based tourism and recreation. Chapters range in focus from cultural issues relating to lake management in New Zealand, to recreational boating activities in Finland, Poland and the Netherlands, to historical accounts of the development of tourism interests around icon lakes in the USA. The obvious challenge for the editors was to bring these diverse case studies together in a sensible and informative framework, such that readers of the book could learn about key aspects of tourism and the recreational use of lakes and other water bodies. To do this, the editors have divided the book into four parts, namely 1. Introductory Context; 2. Historical Dimensions and Cultural Values; 3. Tourist Activities and Perceptions; and 4. Planning and Management Issues. This approach is somewhat chronological and serves to walk the reader through the historical development of lakes as focal sites for tourism and recreation and the wide range of issues that come with the fact that lakes are the source of attention for a wide range of users and stakeholders. An important message conveyed in this book is that tourism and recreation represent relatively recent uses of lake environments and as 
such, opportunities are sometimes limited (and occasionally enhanced) by existing infrastructure and uses of the water resource.

While Lake Tourism is one of the first books to highlight the importance of lake environments to tourism and recreation, the term 'lake tourism' doesn't really adequately summarize the contents of the book. This is due in part to the fact that the editors fail to define what they see as a lake environment. Only in Chapter 2 (by Chris Cooper), 'Lakes as Tourism Destination Resources', is there discussion of the types of aquatic ecosystems that can be considered as lakes. This is a significant shortcoming, for as we might all generally agree on what a lake is, discrimination between reservoirs and natural lakes, for example, can be important in discussions of the types of tourism and recreation and the multitude of other users of these systems and their water. Given this lack of a consistent definition, several of the case study chapters really don't focus on lakes at all (at least not within the list of lake types presented in Chapter 2), with some discussing recreational boating on canals and others simply investigating ‘aquatic tourism and recreation’ which presumably includes use of rivers, streams, lakes and even some coastal water bodies. As the importance of all of these aquatic environments as focal environments for tourism and recreation needs to be recognised and the general issues relating to tourism use of these systems are likely to be broadly similar, perhaps the title Lake Tourism is a little too narrow for the range of systems encountered in this book.

Another definitional problem exists in this book with respect to the use of the term tourism. Specifically, the book chapters seem to switch between the terms tourism and recreation, or at least use them interchangeably. As the nature of visitor 
activities is likely to be strongly influenced by whether visitors are tourists or local residents partaking in recreational activities (Puczko and Ratz 2000, Carr 2002), the inconsistent use of these terms between chapters probably detracts from some of the specific messages the authors and editors are trying to deliver, as readers may not always be able to differentiate between issues relating to tourism, recreation or both. Furthermore, discrimination between the perceptions, activities and values of tourists and residents represents a significant area of research effort (Kozak 2002) that has not been adequately embraced in some of the chapters in this book.

The inconsistent definitions and shifts in focus across chapters make Lake Tourism read more like a collection of water-based tourism and recreation case studies than a succinct and sound treatise of lake tourism, per se. As mentioned earlier, this is more a criticism of the title than of the content of this book, as the larger issue of water-based tourism and recreation is a significant field of research effort and deserves recognition here and in future publications. Furthermore, the issues and case studies presented in this book are interesting, diverse and relevant to a much broader audience than those specifically interested in lake-based tourism and recreation. The book could have been better served by a broader primary title, perhaps something along the lines of Water-Based Tourism and Recreation. Such a title would attract a broader readership and more comfortably encompass some of the recreationonly or broadly aquatic aspects of the case studies that seem a little out of place in a 'lake tourism' book. This also includes some of the messages from the editor's concluding chapter which nominates invasive species, climate change and pollution as significant contemporary threats that may influence the sustainability of tourism ventures in all aquatic environments. Let's hope that Lake Tourism, a valuable 
contribution to get the ball rolling, is the first in a series of releases that serve to further highlight the importance, issues and implications associated with tourism and recreation in, on and around focal aquatic environments.

Wade L Hadwen: Australian Rivers Institute, Griffith University, Nathan Campus, Brisbane, Queensland, Australia 4111. Email <w.hadwen@griffith.edu.au>

\section{REFERENCES}

Carr, N. (2002) A comparative analysis of the behaviour of domestic and international young tourists. Tourism Management 23, 321-325.

Kozak, M. (2002) Comparative analysis of tourist motivations by nationality and destinations. Tourism Management 23, 221-232.

Puczko, L. and Ratz, T. (2000) Tourist and resident perceptions of the physical impacts of tourism at Lake Balaton, Hungary: Issues for sustainable tourism management. Journal of Sustainable Tourism 8, 458-478.

Tuohino, A. and Pitkänen, K. (2004) Selling waterscapes? In: Saarinen, J. and C. M. Hall (eds) Nature Based Tourism Research in Finland: Local Contexts, Global Issues (pp. 129-150). Finnish Forest Institute, Research Papers 916. 